\title{
Fundamentos
}

\begin{tabular}{|c|}
\hline $\begin{array}{l}\text { REsumo } \\
\text { Nesta conferência pretendo } \\
\text { mostrar que o uso de } \\
\text { analogias e comparações do } \\
\text { tipo "como se" corresponde a } \\
\text { um instrumento beurístico de } \\
\text { pesquisa, configurando um } \\
\text { procedimento metodológico de } \\
\text { pesquisa colocado, por Freud, } \\
\text { no quadro das ciências da } \\
\text { natureza. O objetivo, no seu } \\
\text { uso, é tanto fornecer uma } \\
\text { "regra para procurar" quanto } \\
\text { dar a certos conceitos ou } \\
\text { processos um conteúdo } \\
\text { empirico não facilmente } \\
\text { apreensivel ou, até mesmo, } \\
\text { impossivel de ser encontrado. } \\
\text { Essa concepção sobre a } \\
\text { natureza e a função de } \\
\text { analogias e comparações do } \\
\text { tipo "como se" nas ciências } \\
\text { não é uma novidade } \\
\text { introduzida por Freud, mas } \\
\text { sim uma prática comum nas } \\
\text { ciências empiricas, que Freud } \\
\text { aprendeu na sua formação } \\
\text { como homem de ciência. } \\
\text { Nesse sentido, depois de } \\
\text { explicitar as concepçoes de } \\
\text { Immanuel Kant e Ernst } \\
\text { Mach sobre o uso das } \\
\text { analogias e comparações do } \\
\text { tipo "como se", procura-se } \\
\text { retomar as opiniões de Freud } \\
\text { sobre esse tema, mostrando } \\
\text { que essas opiniões reiteram } \\
\text { as concepções dos autores } \\
\text { citados. } \\
\text { Descritores: analogia; } \\
\text { ficção heuristica; ciência; } \\
\text { Freud; Kant; Mach }\end{array}$ \\
\hline
\end{tabular}

\section{O MÉTODO ANALÓGICO EM FREUD ${ }^{1}$}

\author{
Leopoldo Fulgencio
}

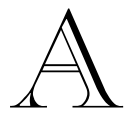

quantidade de analogias e comparações do tipo como se presentes no texto de Freud não é um acidente; ao contrário, aparecem na grande maioria de seus textos, a ponto de encontrarmos na edição das obras completas de Freud em espanhol, organizada por Etcheverry (Amorrortu Editores), uma longa tabela de analogias utilizadas ao longo de toda a obra (Etcheverry, 1988, pp. 299-304).

Defendo que Freud utiliza-as como instrumento de pesquisa no quadro característico das ciências da natureza, cônscio do seu valor heurístico. Não se trata apenas de um traço do estilo de Freud ou, ainda, de uma especificidade do seu teorizar ou mesmo do teorizar em psicanálise, mas também, mais fundamentalmente, de uma prática comum entre os homens de ciência, aprendida por ele na sua formação intelectual.

Não se trata, aqui, de fazer uma discussão crítico-comparativa, retomando as análises feitas sobre o uso de analogias na pesquisa psicanalítica ${ }^{2}$, mas sim de fornecer uma opção para as concepções de

Prof. Dr. da Pontifícia Universidade Católica de Campinas. Membro do Departamento de Psicanálise do Instituto Sedes Sapientiae. Membro do Centro Winnicott de São Paulo.

204 Estilos da Clínica, 2006, Vol. XI, nº 21, 204-223 
Freud sobre o uso metodológico desse dispositivo. Considero que o método analógico em Freud (com o uso de analogias e comparações do tipo como se) corresponde a um dos aspectos de um método especulativo de pesquisa nas ciências empíricas; cujas referências podem ser reconhecidas no programa kantiano de pesquisa a priori para as ciências da natureza e nas práticas de pesquisa empírica próprias ao século XIX, e que caracterizam o ambiente no qual Freud foi educado. Noutro trabalho mostrei as características desse método especulativo e o seu reconhecimento na obra de Freud (Fulgencio, 2003). Grosso modo, mostrei que a metapsicologia freudiana (especialmente no que se refere aos conceitos de pulsão, libido e de aparelho psíquico) são ficções teóricas de valor apenas heurístico, utilizadas tal como Kant preconizara para o uso de ficções heurísticas nas ciências da natureza, e também como era comum encontrar em diversos cientistas no século XIX, entre eles Ernst Mach. ${ }^{3}$ Trata-se, aqui, de desenvolver mais um dos aspectos que podemos desprender da afirmação de Heidegger (2001) sobre Freud, a saber: "A metapsicologia de Freud é a transposição da filosofia neokantiana [da natureza] ao ser humano. Por um lado, ele [Freud] usa as ciências naturais e, por outro, a teoria kantiana da objetividade" (2001, p. 222).

Nesse sentido, focando o problema no caso das analogias e comparações do tipo como se, vou apresentar, primeiramente, o que Kant e Mach têm a dizer sobre as analogias e comparações do tipo como se nas práticas científicas de pesquisa empírica. Segundo, retomar a opinião de Freud sobre esse mesmo tema, mostrando que é partidária do que esses autores disseram; ou seja, adiantando o que será mais à frente detalhado, que elas servem tanto como uma maneira de fornecer conteúdos intuitivos (sensíveis) para melhor aprender determinado processo, fenômeno e dinâmica entre fenômenos, quanto como um esquema para descobrir relações ou elementos até então não conhecidos; um guia para procurar ambos os aspectos considerando que o homem, no que se refere à sua psicologia, deve ser tomado como um objeto tal como qualquer outro objeto da natureza.

\section{As comparações do tipo como se e as analogias no programa de pesquisa kantiano}

Pode-se ler a obra de Kant, especialmente a Crítica da razão pura e o Princípios metafísicos a toda ciência da natureza, como tendo proposto um programa de pesquisa a priori para as ciências da 
natureza (Loparic, 2000). Esse programa apresenta tanto um conjunto de regras como de princípios e conceitos, todos a priori, para a realização de pesquisas empíricas. No que se refere aos conceitos a priori, Kant analisa quais seriam os relativos à nossa faculdade de intuir ou perceber, o da nossa faculdade de julgar ou do entendimento e, terceiro, os da faculdade de argumentar ou a razão propriamente dita. Os dois primeiros tipos de conceitos (referidos à intuição e ao entendimento) são conceitos que poderão encontrar no mundo fenomênico um conteúdo empírico que a eles corresponde de forma adequada, enquanto os conceitos puros da razão são, necessariamente, especulativos, jamais tendo a possibilidade de receberem esse conteúdo de forma adequada. Ao analisar a natureza e a função desses últimos, Kant dirá que, apesar de serem meras entidades especulativas, são utilizados como construções auxiliares para regular o uso sistemático do entendimento no campo da experiência. Diz Kant (1781/1997a): “Os conceitos da razão (...) são meras idéias e não têm, evidentemente, objeto algum em qualquer experiência, mas não designam por isso objetos imaginados e ao mesmo tempo admitidos como possíveis. São pensados de modo meramente problemático, para fundar em relação a eles (como ficções heurísticas) princípios reguladores do uso sistemático do entendimento no campo da experiência. Se sairmos deste campo, são meros seres da razão, cuja possibilidade não é demonstrável e que não podem também, por hipótese, ser postos como fundamento da explicação dos fenômenos reais." (p. 799)

A princípio, esses conceitos puros da razão ou idéias, ${ }^{5}$ são conceitos que tornam possível pensar as totalidades. Eles são redutíveis a três classes, ou unidades: a do sujeito pensante, a da série das condições do fenômeno e, por fim, a da condição de todos os objetos pensantes. Diz Kant: “... a primeira delas contém a unidade absoluta do sujeito pensante [que é o objeto da psicologia], a segunda, a unidade absoluta da série das condições do fenômeno [o conjunto de todos os fenômenos que é objeto da cosmologia] e a terceira, a unidade absoluta da condição de todos os objetos do pensamento em geral [que contém a condição suprema da possibilidade de tudo o que pode ser pensado (o ente de todos os entes) é objeto da teologia].” (p. 391)

Essas idéias fornecem as condições de possibilidade para que a procura do conhecimento do tipo científico possa ser efetuada em termos válidos. Elas mesmas não são objetos da ciência, dada sua natureza de serem apenas idéias sem a possibilidade de referente empírico adequadamente válido. No entanto, elas garantem que tanto a natureza como os costumes sejam conhecidos em termos de suas leis, dentro de um sistema único que pode relacionar os fenômenos segundo suas determinações recíprocas. Dados esses 
princípios, o cientista pode dedicarse à sua tarefa de explicar os fenômenos e suas relações, ou melhor, de resolver problemas empíricos.

No caso da física - enquanto uma ciência empírica -, é necessário supor a natureza como se esta fosse uma totalidade, com todas as suas partes em relação umas com as outras, regidas pelos mesmos princípios de causalidade, ainda que não esteja no campo da percepção a apreensão intuitiva (empírica) dessa totalidade.

No caso da psicologia, também estamos diante do mesmo tipo de necessidade transcendental, a saber, é necessário que tudo aquilo que possa ser considerado um objeto dado ao sentido interno esteja referido a uma única unidade, a alma como uma substância simples, mas isso não pode ser provado empiricamente. ${ }^{6}$ Diz Kant (1781/1997a): “... vamos primeiramente ligar (na psicologia), ao fio condutor da experiência interna, todos os fenômenos, todos os atos e toda a receptividade de nosso espírito como se este fosse uma substância simples, que existe com identidade pessoal (pelo menos em vida), enquanto mudam continuamente os seus estados, entre os quais se encontram os do corpo, mas como condições apenas externas.” (p. 700)

A estrutura da comparação do tipo como se também pode ser dita uma comparação por analogia. Kant diz que a analogia tem um sentido diferente quando usada na matemática e quando usada na filosofia e nas ciências (Kant, 1787/1997b, p. 222). Primeiro ele comenta como a matemática define a estrutura básica da analogia: ela tem uma equação de quatro termos, em que é expressa a igualdade de duas relações quantitativas (A/B $=\mathrm{C} / \mathrm{D}$ ou, por extenso, A está para $\mathrm{B}$ da mesma maneira que $\mathrm{C}$ está para D); dados três desses termos, o quarto pode ser constituido ou construído a partir dessa equação. Todos os quatro termos pertencem a um mesmo conjunto de dados; têm a mesma natureza, por assim dizer. É assim que procedemos normalmente quando aplicamos a regra de três em nossas contas cotidianas.

$\mathrm{Na}$ filosofia e nas ciências, no entanto, as coisas se passam diferentemente. Sendo a expressão da igualdade de duas relações qualitativas, a analogia - por exemplo, quando se diz que as bolas de bilhar (A) movimentam-se numa mesa (B) da mesma maneira que as moléculas de um gás (C) movimentam-se num recipiente fechado (D) - acaba por relacionar termos e fenômenos que não pertencem necessariamente a um mesmo conjunto de dados, podendo ser de domínios e naturezas diferentes. Nessa situação, dados três termos de uma equação analógica, nem sempre será possível chegar diretamente ao quarto termo; ou seja, a relação analógica indica apenas o tipo de relação que se espera seja a mesma (ou parcialmente a mesma) quando comparamos o que ocorre entre "A e B" com o que ocorre entre "C e D".

A equação analógica pode ser uma proposta de relação de proporcionalidade entre seus elementos, mas não é esse seu único sentido. Ela também pode ser proposta em termos de comparações e projeções que associam determinado conjunto de 
dados conhecidos a outro conjunto de dados ainda desconhecido, estabelecendo, num sentido muito amplo, comparações entre dinâmicas de um e outro campo de dados, não necessariamente de mesma natureza (aliás, como é comum ocorrer).

Para Kant, no que diz respeito ao uso das analogias nas ciências, elas são, num primeiro sentido, um tipo de regra para procurar algo que se desconhece em determinado fenômeno ou conjunto de fenômenos; um tipo de esquema para que se possa tentar descobrir um termo ainda não conhecido ou, ainda, descobrir relações desconhecidas a partir do que já é conhecido na experiência sensível.

A analogia é, pois, um tipo de regra para a pesquisa, um esquema que torna possível procurar relações ou termos de uma relação. $\mathrm{Na}$ matemática, a analogia tem o poder de constituir o termo que falta, mas na filosofia e na ciência, diz Kant (1781/ 1997a), ela tem apenas um papel regulativo, jamais um papel constitutivo daquilo que se procura (p. 222).

Um exemplo do próprio Kant, mostrando como a analogia é útil para tentar conhecer determinado campo de dados não passível de observação empírica objetiva, diz respeito ao problema de explicar como funciona e o que é o Estado Monárquico, dado que este não pode ser tomado como um objeto empírico em si mesmo. Se compararmos o Estado Monárquico a um moinho movido à mão, teremos meios não só para pesquisar como para tentar formular leis (empíricas) sobre seu funcionamento, ainda que o Estado não seja, jamais, uma mão e um 
moinho: essa analogia torna-se o símbolo do Estado Monárquico. Por outro lado, as relações que se podem observar num moinho movido à mão podem ser projetadas para um Monarca governando um Estado. Diz Kant (1788/1997b): “um estado monárquico é representado por um corpo animado, se ele é governado segundo leis populares internas, mas por uma simples máquina (como porventura um moinho), se ele é governado por uma única vontade absoluta, em ambos os casos, porém, só simbolicamente. Pois entre um Estado despótico e um moinho não há na verdade nenhuma semelhança, mas certamente entre a regra de refletir sobre ambos e sua causalidade." (p. 197; parágrafo 59, A 256)

Um segundo objetivo ou função das analogias, nas práticas de pesquisa empírica, diz respeito à necessidade de fornecer aos conceitos um conteúdo intuitivo. Diz Kant (1781/1997a): "Pensamentos sem conteúdo são vazios; intuições sem conceitos são cegas. Pelo que é tão necessário tornar sensíveis os conceitos (isto é, acrescentar-lhes o objeto na intuição) como tornar compreensíveis as intuições (isto é, submetê-las aos conceitos)". (p. 75). Nesse mesmo exemplo do Estado Monárquico também se nota que a analogia fornece um conteúdo sensível impossível de obter diretamente.

Assim, pode-se concluir que, para Kant, o uso das analogias nas ciências tem dois objetivos específicos: primeiro, servem como um tipo de regra a ser usada no desenvolvimento das pesquisas empíricas; segundo, como um tipo de esquema (analógico ou simbólico) que torna possível associar conceitos de validade apenas heurística (tal como os conceitos puros da razão, ou idéias) ao mundo sensível, dando-lhes um conteúdo intuitivo, ainda que de forma inadequada ${ }^{7}$.

\section{O proceder analógico para Mach}

Para Mach o uso de analogias é uma prática corriqueira, seja para o homem comum seja para o cientista. ${ }^{8}$

Para o autor, trata-se, tanto para um quanto para outro, de tentar levar o conhecido para o desconhecido, por meio de uma projeção ou uma comparação. Mach refere-se à sua presença em Platão, Aristóteles, na matemática antiga e moderna, ${ }^{9}$ na astronomia (Copérnico, Galileu, Kepler), nos escritos renascentistas, e cita alguns exemplos significativos para a ciência moderna, dentre eles, o caso da teoria da propagação do calor proposta por Fourier (17681830), desenvolvida por analogia com a hidrodinâmica, teoria que, por sua vez, serviu de modelo para explicar outros fenômenos como as correntes elétricas e as de difusão. Diversos outros exem- 
plos poderiam ter sido citados por Mach, ainda que ele não o tenha feito naquele momento: é o caso de Huyghens (1629-1695), que propôs que a propagação da luz no ar fosse compreendida de forma análoga à que ocorre quando da propagação de uma onda na superfície de um líquido e, com isso, elaborou uma teoria ondulatória para a luz; o da teoria cinética dos gases, construída a partir de um modelo que considerava os gases como se fossem compostos por partículas elásticas que respondiam a leis mecânicas; ${ }^{10} \mathrm{o}$ da Ley de Boyle (1627-1691), que relaciona a pressão do gás com seu volume, só formulável após conceber o ar como algo análogo a um fluído elétrico ao qual poderiam ser aplicados todos os conceitos da Hidroestática (Kuhn, 1970, p. 49).

Ao definir o que são as analogias no processo de pesquisa científica, Mach (1905/1920) diz que elas são "uma comparação de relações abstratas entre as características de dois objetos" (p. 227), que constituem um tipo de identidade parcial, uma semelhança abstrata: "se as características comparadas são imediatamente perceptíveis, nós falamos de semelhanças; se são relações abstratas, nós empregamos de preferência a palavra analogia" (p. 232). Ele considera que suas concepções sobre as analogias correspondem, grosso modo, às mesmas de Maxwell (citado por Mach 1905/1920, p. 227): "Entendo por analogia física uma semelhança parcial existindo entre duas classes de fenômenos e que faz com que cada um ilustre o outro". O autor até mesmo credita a Maxwell ter tornado o uso das analogias, na física, um método bem explicado, e descreve, então, a maneira como Maxwell procedeu: "Procurando nos fenômenos eletro-estáticos, magnéticos, etc., trações comuns que lembravam o fenômeno de circulação de um fluído, Maxwell idealizou esse fluído para tornar a analogia completa. Ele supôs que ele era sem massa e incompressível, e que ele corria através de um meio resistente: ele recorreu assim a uma imagem fictícia feita para as necessidades da analogia, mas que não era por isso menos intuitiva. Não se toma essa imagem por alguma coisa real, e se sabe exatamente no que ela está de acordo com o ponto de vista abstrato em relação ao que se quer representar. A pressão do líquido corresponde aos diferentes potenciais, a direção da corrente do líquido a direção da corrente elétrica, a variação da pressão às forças, etc. Maxwell uniu, assim, as vantagens da hipótese à das formulas matemáticas e, segundo uma forte expressão de Hertz (um pouco modificada), as conseqüências físicas da imagem que ele propõe são, por sua vez, as imagens das conseqüências dos fatos. Maxwell se aproxima de um método ideal de pesquisa científica: daí seus sucessos excepcionais." (pp. 235-6)

Nesse primeiro sentido, as analogias serviriam como modelos para apreender os fenômenos, explicar suas relações, tornando possível formular e resolver certos problemas empíricos por meio de uma ficção teórica. O seu propósito é, ao comparar algo conhecido com algo desconhecido, o de levar o cientista a 
descobrir relações não visíveis. Isso, diz Mach, constitui um procedimento cotidiano na pesquisa científica: "Esta mesma análise [na qual Mach defende que o "fisico opera sempre com sensações", que são, por sua vez, as unidades da percepção e do próprio pensamento] nos mostra também que completar em pensamento os complexos de sensações, procedendo por analogia a partir de elementos inobserváveis, ou a partir de elementos tais que eles não podem, de maneira alguma, ser observados, é um exercício praticado quotidianamente pelo cientista." (Mach, 1886/ 1996, p. 43)

Assim, nesse primeiro sentido, as analogias servem como uma forma de tornar mais compreensível determinada explicação ou formulação, fornecendo imagens para o entendimento, ou, então, como um guia para procurar relações entre os fenômenos na experiência.

Num segundo aspecto do uso das analogias, Mach caracteriza-as como uma maneira de fornecer aos conceitos um conteúdo intuitivo, seja para sua intelecção seja para sua utilização, quando esses não têm uma referência empírica claramente reconhecível. Para ele, tal como para Kant, o conhecimento da natureza por meio de conceitos não pode ser um conhecimento apenas abstrato, não podem ser formas vazias, eles precisam ser representados de uma maneira viva associados com o mundo empírico ${ }^{11}$. No entanto, no caso de diversas hipóteses formuladas pelos cientistas, nem sempre essa associação é fácil de ser realizada, o que os leva a usar das analogias como um meio para fornecer a essas hipóteses um conteúdo vivo (intuitivo), ainda que não sejam totalmente adequados: "a compreensão conceitual da natureza deve ser precedida pela sua compreensão mediante a fantasia, a fim de [que se possa] produzir para os conceitos um conteúdo visual vivo" (Mach, 1905/1920, pp. 106-7). O uso de imagens é, para ele, um importante instrumento para auxiliar a compreensão de certos fenômenos de difícil apreensão sensível direta: “... o emprego consciente de imagens é muito proveitoso. Há fatos que nós percebemos imediatamente pelos sentidos; há outros, entretanto, dos quais só tomamos conhecimento através de uma observação complicada e com a ajuda de um sistema de reações abstratas [...] Nós estamos muito mais familiarizados com representações sensíveis intuitivas do que com conceitos abstratos, mas que têm por base representações intuitivas [sensíveis]". (Mach, 1905/1920, pp. 251-2)

Como um terceiro sentido, que caracterizaria o uso das analogias nas ciências, Mach faz referência a certos conceitos fundamentais que, por vezes, serviram como um tipo de orientação para as pesquisas, construídos por analogia a outros fenômenos, tal como o conceito de força na física. ${ }^{12}$ Para ele, esse conceito é antropológico, construído pela projeção, na natureza, da sensação de pressão que sentimos quando de nossos movimentos: "As circunstâncias determinantes de movimento que nos são mais bem conhecidas são nossos próprios atos voluntários, dependentes da inervação. Nos movi- 
mentos que nós mesmos provocamos, como também naqueles que as circunstâncias exteriores nos obrigam, ressentimos sempre certa pressão. Daí nosso hábito de figurar, a nós mesmos, toda circunstância determinante de movimento como análoga a um ato de vontade, como uma pressão." (Mach, $1883 / 1987$, p. 81 )

Para Mach, o conceito de força, na física, não é, pois, uma realidade empírica, mas tão somente uma convenção; da mesma maneira que Kant analisou no seu programa de pesquisa considerando o ponto de vista dinâmico e a idéia de força motriz que a ele corresponde a mais útil, e não a mais verdadeira, para servir como o tipo de princípio causal para explicar os movimentos na natureza; enfim, mero nome para a "circunstância que tem o movimento por conseqüência” (Mach, 1883/1987, p. 81) ou, ainda, um tipo de mitologia científica (Mach, 1905/1920, p. 113).

Esses três sentidos ou funções do método analógico nas ciências estão em consonância com o valor heurístico creditado por Mach a conceitos que caracteriza como representações-fantasia (Phantasie-Vorstellungen) (Mach, 1905/1920, p. 163); representações úteis no processo de descobertas das relações efetivas (empíricas) entre os fenômenos, mas que têm apenas uma validade heurística, devendo, com o amadurecimento da ciência, "ser aniquiladas, pela crítica implacável, tendo em vista os fatos, antes que uma delas possa desenvolver-se e ter uma permanência mais longa" (Mach, 1905/1920, p. 113). 
A proximidade entre Kant e $\mathrm{Mach}^{13}$, no que se refere ao método analógico, diz respeito à natureza e à função desse instrumento de investigação, tanto para um como para outro; o método analógico serve para organizar a experiência, auxiliar na apreensão e na procura de relações para explicar os fenômenos, ele é um instrumento para a formulação e resolução de problemas empíricos.

\section{O proceder analógico para Freud}

Não há, em Freud, um texto dedicado a explicitar como e por que ele usa, de forma tão constante, as comparações e analogias. Trata-se de um uso tácito do qual, em ocasiões esparsas, ele apresenta alguns comentários sobre seu proceder, identificando-o como uma prática corriqueira nas outras ciências empíricas. A utilização das analogias é intensificada quando a observação direta dos fenômenos não é possível ou não é evidente, quando a analogia torna mais clara a intelecção do que já foi ou está sendo teorizado; ou, ainda, para esclarecer determinado conceito ou processo sem acesso empírico possível ou evidente. Ainda que não exista uma teoria freudiana versando sobre as analogias, podemos reunir alguns dos seus trabalhos nos quais ele explicita porque as considera necessárias, especificando ainda qual o valor epistemológico a ser creditado a essas comparações, bem como os seus limites, deficiências e modos de uso.

Para Freud, o psiquismo corresponde a um vasto campo do qual conhecemos, por observação direta, apenas dois dos seus pólos: "de um lado, seu órgão somático, o lugar de sua ação, o cérebro (ou o sistema nervoso) e, de outro lado, nossas atividades conscientes das quais temos conhecimento direto e que nenhuma descrição nos faria conhecer melhor" (Freud, 1940/1985, p. 3). O que se supõe existir entre esses dois pólos - tudo aquilo que Freud associou a um inconsciente do ponto de vista dinâmico, com pulsões, repressões, libido, isso-eu-supereu, etc. - corresponde a uma zona obscura. Freud chega a dizer: "A psicanálise supõe um postulado fundamental [o aparelho psíquico] que cabe à filosofia discutir, mas cujos resultados justificam o valor" (Freud, 1940/1985, p. 3). As hipóteses sobre essa zona obscura foram elaboradas a partir dos dados da observação clínica, mas esses dados descritivos não são suficientes para explicar o que se observa, o que obriga Freud a buscar recursos analógicos especulativos. É justamente nessa operação que surge a necessidade de aplicar analogias para entender os fenômenos psíquicos. Ao 

com o tema com o qual me ocupo e que não se acordam entre elas. Reconheço isso e, de forma alguma, arrisco subestimar-lhes o valor, mas, se prossigo com esses paralelos, é a fim de tornar compreensível, por diversas aproximações, as idéias extremamente complicadas e nunca antes expostas. Concedo-me assim a liberdade de continuar, nas páginas seguintes, a me servir dessas comparações, tão discutíveis quanto elas possam ser." (Freud, 1895/2002, p. 235)

Freud está ciente de que suas analogias e comparações têm apenas uma validade parcial, que são limitadas e que "jamais nos levam muito longe” (Freud,1937/1995, p. 251). Ele mesmo relativiza sua aplicação ao tentar explicar, por meio de uma analogia, quais os procedimentos disponíveis às intenções do eu. Freud propõe que pensemos num livro proibido, quando os livros ainda eram manuscritos e aquele que o copiava usava uma série de artifícios para ocultar e deformar o proibido. Seu comentário denota já a preocupação com a delimitação da comparação: "Se não persistirmos numa comparação ao pé da letra [de maneira estrita], podemos dizer que a repressão [Verdrängung], assim como outros métodos de defesa, tem a mesma relação que a omissão tem com a deformação do texto e, nas diferentes formas dessa falsificação, podese encontrar as analogias com a diversidade da modificação do eu. Pode-se tentar objetar que, num ponto essencial, essa comparação derrapa, pois a deformação do texto é obra de uma censura tendenciosa para a qual o desenvolvimento do eu não tem contrapartida. Mas não é assim, pois esse caráter tendencioso é em grande parte representado pela imposição do princípio do prazer." (Freud, 1937/1995, p. 252)

As analogias são construções auxiliares para ajudar na descoberta de fenômenos ou relações entre os fenômenos. Elas servem apenas como um guia para pesquisar e, nesse sentido, podem ser consideradas instrumentos que são abandonados, uma vez atingido o objetivo perseguido, ou ainda hipóteses a serem verificadas. No primeiro caso, elas são como andaimes para a construção de um edifício (teórico), e como tais devem ser mantidas, jamais como sendo, elas mesmas, a teoria que corresponde aos fatos empíricos propriamente ditos. Diz Freud: "Eu estimo que nós temos o direito de dar livre curso a nossas suposições [Vermutugen], desde que preservemos a cabeça fria e não tomar os andaimes pelo edifício. E uma vez que, em nossa primeira abordagem de algo desconhecido, tudo de que precisamos é o auxílio de representações auxiliares, daremos preferência, inicialmente, às hipóteses de caráter mais tosco e mais concreto." (Freud, $1900 / 2003$, p. 589) ${ }^{14}$

No segundo caso - as analogias como hipóteses a serem verificadas -, trata-se de utilizá-las como um objetivo a ser atingido de forma lenta, tateante e laboriosa, tal como noutras ciências, aproximando o conhecido ao que ainda não foi dado pela observação: "Avança-se por suposições, fazem-se construções auxiliares que são retiradas se não se confirmam, tem-se necessidade de muita 
paciência, de disponibilidade para todas as possibilidades, renuncia-se a convicções primeiras para não absterse, constrangido por elas, de ver fatores novos inesperados (...). Só existe ajuda à pesquisa via a experimentação pela qual se deve passar numa análise.” (Freud, 1933/2004a, p. 259)

Freud lembra que suas proposições têm apenas um valor aproximativo, mas isso também é assim em outros ramos da ciência, o que reitera a pertinência da teoria freudiana ao ponto de vista heurístico, no que diz respeito ao valor a ser dado às suas teorias.

"Os processos de que se ocupa [a psicanálise] são, em si mesmos, tão incognoscíveis como o de outras ciências, químicas ou físicas. Contudo, é possível estabelecer as leis a que obedecem, perseguir seus vínculos recíprocos e suas relações de dependência sem deixar lacunas por longos trechos - ou seja, o que se designa como compreensão no âmbito dos fenômenos naturais em questão. Para isso, não se pode prescindir de novas suposições nem da criação de conceitos novos. Estes não devem, porém, ser menosprezados como testemunhos de nossos embaraços [apuros], mas sim estimá-los como enriquecimentos da ciência; eles possuem títulos que lhes podem ser outorgados, na qualidade de aproximações, têm o mesmo valor que as correspondentes construções intelectuais auxiliares de outras ciências naturais, e esperam ser modificados, retificados e receberem uma definição mais fina mediante uma experiência acumulada e depurada." (Freud, 1940/1985, p. 21)
A questão a ser colocada é a de saber o que é que justifica o uso dessas comparações imprecisas, parciais e limitadas. Para Freud, trata-se de saber que vantagem uma analogia pode fornecer para o entendimento, quando não é possível adquiri-lo por outros meios. Ao propor, por exemplo, uma interpretação psicanalítica para o tabu, ele sabe que suas hipóteses não podem ser comprovadas, mas não é isso o fundamental, o importante é que elas possibilitam um conhecimento sobre o psiquismo humano até então não formulado, mesmo que ele seja especulativo. Diz Freud, em Totem e tabu: "Queremos agora saber qual valor pode pretender nossa assimilação do tabu à neurose obsessiva e a concepção do tabu que oferecemos fundando-nos nesta comparação. Tal valor só é evidente se nossa concepção oferece uma vantagem que não se pode obter de outra maneira, se ela permite uma melhor compreensão do tabu não poderíamos obter de outra maneira. Somos talvez inclinados a afirmar que já trouxemos, no que precede, a prova da qual se pode tirar partido; devemos, todavia, tentar reforçá-la, prosseguindo, em detalhe, na explicação dos interditos e usos do tabu." (Freud, 1913/2005a, p. 61)

Freud afirma: "A analogia não teria valor se ela não se deixasse seguir mais à frente" (Freud, 1925/ 1992, p. 142). Ou seja, é o seu valor heurístico que justifica sua aplicação, e não o seu valor enquanto hipótese empírica verificável ou comprovável. Ao fazer uma analogia, afastase aquilo que não interessa para que 
ela possa "tornar visível" determinado fenômeno ou determinadas relações que não são visíveis em si mesmas. É justamente o que faz Freud, ao comparar nossa percepção e memória com um brinquedo chamado de bloco-mágico, figurando tanto uma estrutura como uma dinâmica de funcionamento. Diz Freud: "As pequenas imperfeições do instrumento não têm para nós realmente nenhum interesse, sendo dado que nós queremos nos ligar somente ao que o aproxima da estrutura do aparelho de percepção anímica. (...) Se imaginamos que, enquanto uma mão escreve na superfície do bloco-mágico, uma outra destaca, periodicamente, do tablete de cera a folha de cobertura, ter-se-ia aí uma forma de tornar visível a maneira como eu quis representar o funcionamento de nosso aparelho anímico." (Freud, 1925/1992, pp. 141-3)

Em termos gerais, para Freud, as analogias auxiliam na visualização ou na procura de relações de determinação de determinado fenômeno ou conjunto de fenômenos não observáveis diretamente ou pouco visíveis. Num outro sentido, as analogias servem pra fornecer um conteúdo intuitivo a processos e/ou conceitos difíceis de serem apreendidos. Note-se, por exemplo, quando Freud comenta, em termos metapsicológicos, qual é o objetivo do tratamento psicanalítico: "Lá onde estava o Id, eu devo advir. Trata-se aí de um trabalho cultural, mais ou menos como a secagem do Zuyderzee" (Freud, 1933/2004a, p. 163). Ou seja, tratase de aumentar ou tornar habitável um lugar para viver; no caso, um lugar no qual o eu tem mais autonomia e não é determinado, invadido, pelos impulsos do Id.

Nessa mesma direção que caracteriza o uso das analogias como tendo a função de fornecer conteúdos empíricos a determinados conceitos também temos um caso especial, que diz respeito aos conceitos de natureza especulativa - para os quais jamais será possível obter um conteúdo empírico que lhes seja adequado; cabe, então, às analogias, a função de fornecerem conteúdos intuitivos a esses conceitos, por assim dizer, de forma inadequada. Para Freud, o conceito de pulsão é uma convenção necessária: "Um conceito fundamental convencional, provisoriamente ainda muito obscuro, mas do qual nós não podemos prescindir em psicologia, é o conceito de pulsão" (Freud, 1915/2005b, p. 164). Noutros momentos, diz que as pulsões são seres míticos (Freud, 1933/2004a, p. 95; Freud 1933/2004b, p. 211). Ora, tomando as pulsões como seres míticos ou como convenções, não está em questão perguntar sobre seus referentes empíricos. Para Freud, as pulsões são nada mais que instrumentos heurísticos, são forças de natureza psíquica, análogas às forças de atração e repulsão consideradas na física. ${ }^{15}$ No entanto, Freud considera, seguindo a afirmação de Kant, ${ }^{16}$ que os conceitos 
precisam, para ter validade, mesmo que heurística, um conteúdo sensível (intuitivo), o que o leva, logo após ter dito o que citei acima, a procurar preencher o conteúdo dessa convenção - "Tentemos, partindo de diversos lados, preencher seu conteúdo" (Freud, $1915 / 2005$ b, p. 164) - por meio de uma série de analogias com outros fenômenos, tais como as analogias com os processos fisiológicos, com os estímulos e o arco-reflexo, e com os processos biológicos, relativos às tendências e finalidades dos funcionamentos dos seres vivos. No entanto, ele sabe que isso não significa dar um referente empírico para algo que é apenas uma ficção.

Para concluir, pode-se dizer que, para Freud, as analogias exercem, num sentido, uma função pedagógica ou intelectiva, tornando possível compreender determinada situação ou conjunto de relações; noutro, elas oferecem um guia para procurar relações, procurar termos que faltam a uma relação; e, além disso, tornam possível fornecer conteúdos intuitivos a certos conceitos e/ou modelos meramente especulativos, sem os quais, estes não seriam aplicáveis aos problemas empíricos aos quais se referem enquanto instrumentos heurísticos, instrumentos para ajudar na descoberta das relações efetivas (empíricas) entre os fatos observáveis.

Freud considera que o psiquismo foi, com a psicanálise, tomado como um objeto passível de ser entendido como qualquer outro das ciências naturais (1933/2004a). É justamente por isso que as analogias e comparações do tipo como se, em Freud, são sempre referidas a sistemas naturalizados; ou seja, a "maquinas" cujos elementos podem ser figurados agindo uns sobre os outros, de maneira a ser possível visualizar a série e o tipo de causalidade, sem lacunas, que os explica. Mais ainda, as analogias e comparações mais significativas para a construção da psicanálise como uma ciência são as que supõem que o psiquismo é tomado como se fosse uma máquina, impulsionado por forças e energias análogas (mas não iguais) às que são supostas agirem na natureza; ou seja, as propostas conceituais estruturais da metapsicologia freudiana. É justamente essa operação que faz a grandeza e o ponto fraco de Freud: ao naturalizar o psiquismo, ele pretendeu levar para a psicologia para o campo da ciência, considerando o homem, no que se refere à sua psicologia, um ente que funciona regido pelo mesmo tipo de lei que rege os objetos naturais e, ao fazê-lo, criticam-no alguns autores ${ }^{17}$, tomou o homem pelo que ele não é, falseando seu objeto. É justamente essa perspectiva que naturaliza e objetifica o homem, numa proposta de psicologia científica que reitera o kantismo de Freud, bem como sua pertinência a uma concepção heurística de ciência, característica da formação de Freud no século XIX.

218 Estilos da Clínica, 2006, Vol. XI, nº 21, 204-223 


\section{Fundamentos}

\section{Abstract}

\section{THE ANALOGICAL METHOD IN FREUD}

In this conference, I intend to show that the use of analogies and comparisons of the type "as if" corresponds to a heuristic instrument of research, configuring a methodological procedure of research put by Frend in the setting of the sciences of nature. The goal in his use is both to furnish a "rule of searching" and to give to some concepts, or processes, an empirical content, not easily apprehensible, or even impossible to be found. This conception about nature and the function of analogies and comparisons of the type "as if" in sciences is not a novelty introduced by Freud, but a common practice in empirical sciences, which Freud has learnt in his education as scientist. In this way, after explaining the conceptions of Immanuel Kant and Ernst Mach about the use of analogies and comparisons of the type "as if", I try to recapture Frend's opinions about this issue, showing that they reaffirm the conceptions of those authors.

Index terms: Analogy; heuristic fiction; science; Freud; Kant; Mach

\section{Resumen}

\section{EL MÉTODO ANALÓGICO EN FREUD}

En esta conferencia me propongo demostrar que el uso de analogías y de comparaciones del tipo "como si" corresponden a un instrumento beuristico que configura un procedimiento metodológico de investigación. Este es ubicado por Freud en el cuadro de las ciencias de la naturaleza. El objetivo, cuando se usa tal instrumento, es tanto el de proveer una "regla para buscar" cuánto para dar a ciertos conceptos o procesos un contenido empírico, el cual no es fácilmente aprehensible e, incluso, a veces, imposible de ser encontrado. Esta concepción sobre la naturaleza y la función de analogías y comparaciones del tipo "como si" no es una novedad introducida por Freud sino una práctica común en ciencias empiricas que él aprendió en su formación como hombre de la ciencia. En esta dirección, después de explicitar las concepciones de Immanuel Kant y de Ernst Mach, vuelvo a tomar las opiniones de Freud sobre este tema, mostrando que ellas reiteran las ideas de estos autores.

Palabras clave: Analogía; ficción beurística; ciencia; Freud; Kant; Mach 
REFERÊNCIAS BIBLIOGRÁFICAS

Assoun, P-L. (1981). Introduction à l'épistemologie freudienne. Paris: PUF.

(1985a). Étude-préface. Musil, lecteur de Mach. In F. H. Ellenberger, Histoire de la découverte de l'inconscient. Paris: Fayard. (1985b). Étude-posface. De Mach a la philosophie-sans-qualités. In F. H. Ellenberger, Histoire de la découverte de l'inconscient. Paris: Fayard.

(1995). Imaginaire métapsychologique. Théorie et fantasme chez Freud. Texte (Revue), l'imaginaire de la théorie, 17/18, pp. 217-232, Canadá.

Etcheverry, J. L. (1988). Indice de analogías. In S. Freud, Sigmund Freud obras completas. Indices y bibliografias. (Vol. 24, pp.299-304). Buenos Aires: Amorrortu editores.

Fédida, P. (1994). Pour une métapsychologie analogique. Fécondité de l'hétérogène. In Somatisation, psychanalyse et sciences $d u$ vivant. Paris: Eshel.

Freud, S. (1985). Abrégé de psychanalyse. Paris: PUF. (Trabalho original publicado em 1940)

(1992). Notes sur le 'Bloc Magic'. In S. Freud, Oeuvres complètes psychanalyse. OCF.P, Vol. 17. Paris: PUF. (Trabalho original publicado em 1925)

(1995). L'analyse avec fin et l'analyse sans fin. In S. Freud, Résultats, idées, problèmes, Tome 2. Paris: PUF. (Trabalho original publicado em 1937)

(2000). Leçons d'introduction à la psychanalyse. In S. Freud, Oeuvres complètes psychanalyse. OCF.P, Vol. 14. Paris: PUF. (Trabalho original publicado em 1917) (2002). Études sur l'bystérie. Paris: PUF. (Trabalho original publicado em 1895) (2003). L'Interprétation des rêves. In S. Freud, Oeuvres complètes psychanalyse. OCF.P, Vol. 4. Paris: PUF. (Trabalho original publicado em 1900) (2004a). Nouvelles suite des leçons d'introdution à la psychanalyse. In S. Freud, Oeuvres complètes psychanalyse. OCF.P, Vol. 19. Paris: PUF. (Trabalho original publicado em 1933)

(2004b). Pourquoi la guerre? In S.

Freud, Oeuvres complètes psychanalyse. OCF.P, Vol. 19. Paris: PUF. (Trabalho original publicado em 1933)

(2005a). Totem et tabou. In S. Freud, Oeuvres complètes psychanalyse. OCF.P, Vol. 11. Paris: PUF. (Trabalho original publicado em 1913)

(2005b). Pulsions et destin des pulsions. In S. Freud, Oeuvres complètes psychanalyse. OCF.P, Vol. 13. Paris: PUF. (Trabalho original publicado em 1915)

Fulgencio, L. (2003). As especulações metapsicológicas de Freud. Natureza bumana, 5(1), 127-164.

(2004). O projeto como uma metáfora biológica dos processos psíquicos. Psicologia USP, 15(3), 117-135.

Heidegger, M. (2001). Seminários de Zollikon. Petrópolis: Educ/ABD/Vozes.

Kant, I. (1993). Crítica da faculdade do juízo. Rio de Janeiro: Forense Universitária. (Trabalho original publicado em 1793)

(1997a). Crítica da razão pura (2a ed.). Traduzido a partir da edição crítica de Raymund Schimidt (1956). Lisboa: Fundação Calouste Gulbenkian, 1997. (Trabalho original publicado em 1781).

(1997b). Crítica da razão prática (A. Mourão, trad.). Lisboa: Edições 70. (Trabalho original publicado em 1788)

Kuhn, T. S. (1970). A estrutura das revoluções cientificas. São Paulo: Perspectiva.

Lacan, J. (1975). O seminário, livro 1: Os escritos técnicos de Freud. Rio de Janeiro: Zahar.

Loparic, Z. (1984). Resolução de problemas e estrutura de teorias em Mach. Cadernos de História e Filosofia da Ciência, 6, 35-62. (2000). A semântica transcendental de Kant. Campinas: CLE. 


\section{Fundamentos}

Mach, E. (1920). Erkenntnis und irrtum. [Conhecimento e erro]. Leipzig : Barth. (Trabalho original publicado em 1905)

(1987). La mécanique : Exposé histo-

rique et critique de son développement. Paris : Jacques Gabay. (Trabalho original publicado em 1883)

(1996). L'analyse des sensations: Le rapport du physique au psychique. Paris : Éditios Jacqueline Chambon. (Trabalho original publicado em 1886)

Mezan, R. (1995). Metapsicologia/fantasia. In Figuras da teoria psicanalítica. São Paulo: Escuta/Edusp.

Nagel, E. (1978). La estrutura de la ciencia: Problemas de la lógica de la investigation cientifica ( $3^{\text {a }}$.ed.). Buenos Aires: Paidós.

Shakow, D. \& Rapaport, D. (1964). Nineteenth and early twentieth century background. Psychological Issues, 14 (1), Monograph 13: The influence of Freud on the american psychology.

\section{NOTAS}

1 Este artigo é um dos resultados da minha pesquisa de doutorado, desenvolvida com o apoio do CNPq e da FAPESP. A perspectiva de interpretação da obra de Freud aqui apresentada insere-se na linha de pesquisa do Grupo de Pesquisa em Filosofia e Práticas Psicoterápicas, desenvolvida no Programa de Estudos Pós-Graduados em Psicologia Clínica da PUCSP, a partir dos trabalhos de Zeljko Loparic. Todos os textos citados de originais em línguas estrangeiras foram traduzidos por mim.

2 Alguns estudos expressivos nessa direção já foram feitos por Fédida (1994), Assoun (1995), Mezan (1995).

3 A proximidade entre Freud e Mach já foi alvo de análise, dentre elas, por exemplo, Assoun (1981, 1985a, 1985b). 
${ }^{4}$ Um estudo detalhado da função heurística dos conceitos em Kant também deveria referir-se ao que ele chama de "heautononomia": regra usada pelo juízo reflexivo para viabilizar suas investigações da natureza como sistema. Cf. Kant, 1793/1993, \& V da Introdução, AK XXIX-XXXVIII; trad. pp. 25-30.

5 Kant faz uma análise dos conceitos puros da razão na Crítica da raz̃ão pura, pp. 366396. Veja a análise de Loparic, 2000, Cap. 5.

6 Temos, como na física, dois tipos de psicologia: uma racional ou transcendental e outra empírica. Assim, a alma, enquanto unidade absoluta do sujeito pensante (o eu transcendental), não pode ser objeto de um estudo empírico, mas só de uma psicologia transcendental, não havendo possibilidade, pois, de uma psicologia empírica que se dedicasse ao estudo do eu transcendental. No entanto, a psicologia empírica não trataria do homem transcendental, mas do homem empiricamente dado e das suas determinações (do seu eu empírico, do jogo de relações causais entre as suas representações, etc.). Veja em Fulgencio (2004) uma análise do lugar da psicologia empírica no sistema de Kant e uma distinção entre uma psicologia racional (transcendental) e uma psicologia empírica, bem como a distinção entre uma antropologia do ponto de vista pragmático e uma antropologia do ponto de vista fisiológico (enquanto lógica da physis, o que envolve a física e a psicologia como ciências naturais).

${ }^{7}$ Esses não são os únicos aspectos que se referem ao tema das analogias na obra de Kant, basta lembrar dos princípios do entendimento, os quais oferecem regras gerais para organizar nossas percepções, ordenando-as no tempo (princípios denominados por Kant "analogias da experiência"). Não se trata aqui de seguir todos os sentidos e aspectos desse tema em Kant, mas tão somente de comentar um dos sentidos específicos que diz respeito às regras aplicáveis à pesquisa empírica da natureza.
8 A apresentação das concepções de Mach sobre o método analógico são apresentadas aqui a partir de seu livro, Conhecimento e erro, de 1905, cap. XIII e XIV.

${ }^{9}$ Ele diz, sobre a relação entre a matemática e a física: "Todas as aplicações da matemática à física repousam sobre considerações de analogias entre os fenômenos da natureza e as operações de cálculo" (Mach, 1905, p. 229).

10 Cf. em Nagel (1978), uma análise sobre o tema das analogias nas ciências. Para ele o modelo analógico serviu, na história das ciências, como um guia "para estabelecer suposições fundamentais da teoria e como fonte de sugestão para estender o âmbito de sua aplicação" (p. 110).

${ }^{11}$ Kant diz a mesma coisa: "Pensamentos sem conteúdo são vazios; intuições sem conceitos são cegas. Pelo que é tão necessário tornar sensíveis os conceitos (isto é, acrescentar-lhes o objeto na intuição) como tornar compreensíveis as intuições (isto é, submetê-las aos conceitos)" (Kant, 1781/1997a, p. 75).

${ }^{12}$ Cf. uma série de comentários de Mach sobre a história do conceito de força em seu capítulo sobre o desenvolvimento dos princípios da dinâmica em seu livro dedicado à exposição histórico-crítica do desenvolvimento da Física (1883/1987, pp. 117-256).

13 Sobre o kantismo de Mach, veja Loparic (1984). Um ponto específico mereceria ser discutido, no que se refere à opinião de Kant e Mach sobre a necessidade ou provisoriedade das ficções heurísticas na pesquisa científica, mas isso mudaria o foco desta análise.

14 É notável que Lacan (1975), apoiado em Freud, mostre-se desenvolto na proposição de figurações e esquemas do tipo como se, para o desenvolvimento de suas elaborações teóricas. Depois de citar Freud - "A tentativa de adivinhar, a partir de uma tal decomposição [dos sistemas que comporiam o apa- 


\section{Fundamentos}

relho] a composição do instrumento anímico, pelo que sei, ainda não foi feita. Ela me parece inofensiva. Eu estimo que nós temos o direito de dar livre curso a nossas suposições, desde que, assim fazendo, mantenhamos a cabeça fria sem tomar os andaimes pela construção" -, Lacan comenta: "Inútil dizer-lhes que, como os conselhos são dados para não serem seguidos, não deixaremos desde então de tomar o andaime pelo prédio. Por outro lado, a autorização que Freud nos dá de utilizar relações auxiliares para nos aproximarmos de um fato desconhecido, me incitou a dar provas de uma certa desenvoltura para construir esquemas" (Lacan , 1975, p. 92).

15 Convém, aqui, lembrar, para caracterizar a hipótese de Freud de que há forças no psiquismo, o que ficou conhecimento como o juramento epistemológico de Ernst Brücke e Emile du Bois-Reymond, dado que Freud foi educado no Laboratório de Fisiologia de Viena, dirigido por Brücke: "Brücke e eu [Bois-Reymond] nos comprometeremos a impor esta verdade, a saber, que somente as forças físicas e químicas, com exclusão de qualquer outra, agem no organismo. Nos casos que não podem ser explicados, no momento, por essas forças, devemos nos empenhar em descobrir o modo específico ou a fonte de sua ação, utilizando o método físicomatemático, ou então postular a existência de outras forças, equivalentes em dignidade, às forças físico-químicas inerentes à matéria, redutíveis à força de atração e repulsão" (Shakow \& Rapaport, 1964, p. 34).

16 Diz Kant: "Para cada conceito exige-se primeiro a forma lógica de um conceito (pensante) em geral e, em segundo lugar, a possibilidade de dar-lhe um objeto a que se refira. Sem este último, não possui sentido, é completamente vazio de conteúdo (...) sem isso [os conceitos] não possuem qualquer validade objetiva, são um mero jogo, quer da imaginação, quer do entendimento, com suas res- pectivas representações" (Kant, 1781/1997a, p. 298).

17 Entre eles, no campo da filosofia, podemos citar dois nomes maiores da filosofia no século XX, Ludwig Wittgenstein e Martin Heidegeer; e, no campo, da própria psicanálise, autores como Heinz Kohut, Heinz Hartmann, Roy Schafer, Georges Klein, etc. Além disso, convém também citar a própria proposta de Lacan, na sua tentativa de recolocar a teoria psicanalítica em bases ontológicas díspares das que Freud inicialmente propôs. As pesquisas iniciadas por Zeljko Loparic, no estudo da história da psicanálise e na articulação entre a obra de Heidegger e a de Winnicott, também reitera essa mesma crítica ao paradigma (termo usado aqui no sentido técnico dado por Thomas Kuhn) proposto por Freud na construção da psicanálise como ciência natural. ful@that.com.br

Recebido em maio/2006. Aceito em setembro/2006. 